\title{
Vultures vs livestock: conservation relationships in an emerging conflict between humans and wildlife
}

\author{
Antoni Margalida, David Campión and José A. Donázar
}

\begin{abstract}
Human-wildlife conflict is emerging as an important topic in conservation. Carnivores and birds of prey are responsible for most conflicts with livestock and game but since the mid 1990s a new conflict is emerging in south-west Europe: the presumed killing of livestock by griffon vultures Gyps fulvus. Lack of scientific data and magnification of the problem by the media are increasing alarm amongst the public, and political pressures to implement management decisions have not been based on scientific evidence. We compiled information on 1,793 complaints about attacks by griffon vultures on livestock, lodged with Spanish authorities from 1996 to 2010. Spain is home to the majority (95\%) of griffon vultures and other scavengers in the European Union. Most of the cases occurred in areas of high livestock density, affected principally sheep (49\%) and cows (31\%), and were associated with spring birthing times (April-June). On average $69 \%$ of the complaints made annually were rejected because of a lack of evidence about whether the animal was alive before being eaten. The total economic cost of compensation was EUR 278,590 from 2004 to 2010 . We discuss possible ways to mitigate this emerging human-wildlife conflict. These need to include the participation of livestock farmers, authorities, scientists and conservation groups.
\end{abstract}

Keywords Behavioural changes, ecosystem services, predation, vulture, wildlife damage management

\section{Introduction}

T uman-wildlife conflicts probably have an ancient 1 origin, perhaps starting in the Neolithic period, and coincide with the sedentarization of human populations, the domestication of some animal species and the beginning of intensive exploitation of the environment

ANTONI MARGALIDA* (Corresponding author) Division of Conservation Biology, Institute of Ecology and Evolution, University of Bern, Baltzerstrasse, 6, 3012 Bern, Switzerland. E-mail antoni.margalida@iee.unibe.ch

DAVID CAMPIÓN Gestión Ambiental de Navarra S.A., Pamplona, Navarra, Spain

José A. DonÁZAR Department of Conservation Biology, Estación Biológica de Doñana, CSIC, Sevilla, Spain

* Present address: Department of Animal Production (Division of Wildlife), Faculty of Life Sciences and Engineering, University of Lleida, Av. Alcalde Rovira Roure, 191, 25198 Lleida, Spain

Received 21 February 2012. Revision requested 12 May 2012.

Accepted 6 June 2012. First published online 28 January 2014.
(Anderson, 1997). However, in modern times, with the increase in the human population, the occupation of wilderness and the subsequent need to monetize natural resources, the confrontations between wildlife and people are becoming more common and of increasing concern to ecologists and managers (Treves et al., 2009; Gehring et al., 2010). This conflict mostly reflects a common scenario of unstable coexistence in which large herbivores and predators (mainly carnivores and birds of prey) damage crops, fisheries, livestock and properties and jeopardize human safety (Peterson et al., 2010). This conflict frequently results in persecution of conservation target species, even within protected areas (Graham et al., 2005; Peterson et al., 2010).

Other groups of species, however, have traditionally been respected, not only because they do not represent a conflict with human interests but also because they provide useful services (although some people ignore the value they provide). Vultures and other large-bodied scavengers have, for millennia, yielded an ecosystem service by eliminating carcasses that would otherwise be carriers of disease (Sekercioglu et al., 2004). However, because of profound changes in European agro-grazing systems in the last century, vulture populations have fallen into crisis, declining severely in several European countries (Donázar et al., 1996). Consequently, avian scavengers, and especially griffon vultures (Gyps spp.), are now targets for conservation action. In southern Europe a panoply of management measures over the last 30 years has facilitated a spectacular recovery ( $>200 \%$ in 20 years) of the Eurasian griffon vulture Gyps fulvus population in the Iberian Peninsula and other regions of western Europe (Donázar et al., 2009b). As a result, the Iberian Peninsula is home to the majority (95\%) of griffon vultures and other scavengers in the European Union (Margalida et al., 2010).

This successful conservation strategy is now at risk because of an emerging wildlife-human conflict that emerged in the 1990s: attacks by griffon vultures on livestock. This conflict has intensified in the last decade, causing major unrest among farmers but receiving scarce attention from the scientific community (Margalida et al., 2011a). In the face of the public outcry because of attacks on livestock attributed to vultures, there is a need for an objective assessment of this problem and any implications it has for the management and conservation of scavenger populations. Our purpose here is to explore this emerging issue, examining the human, economic and conservation dimensions of this unusual conflict. 

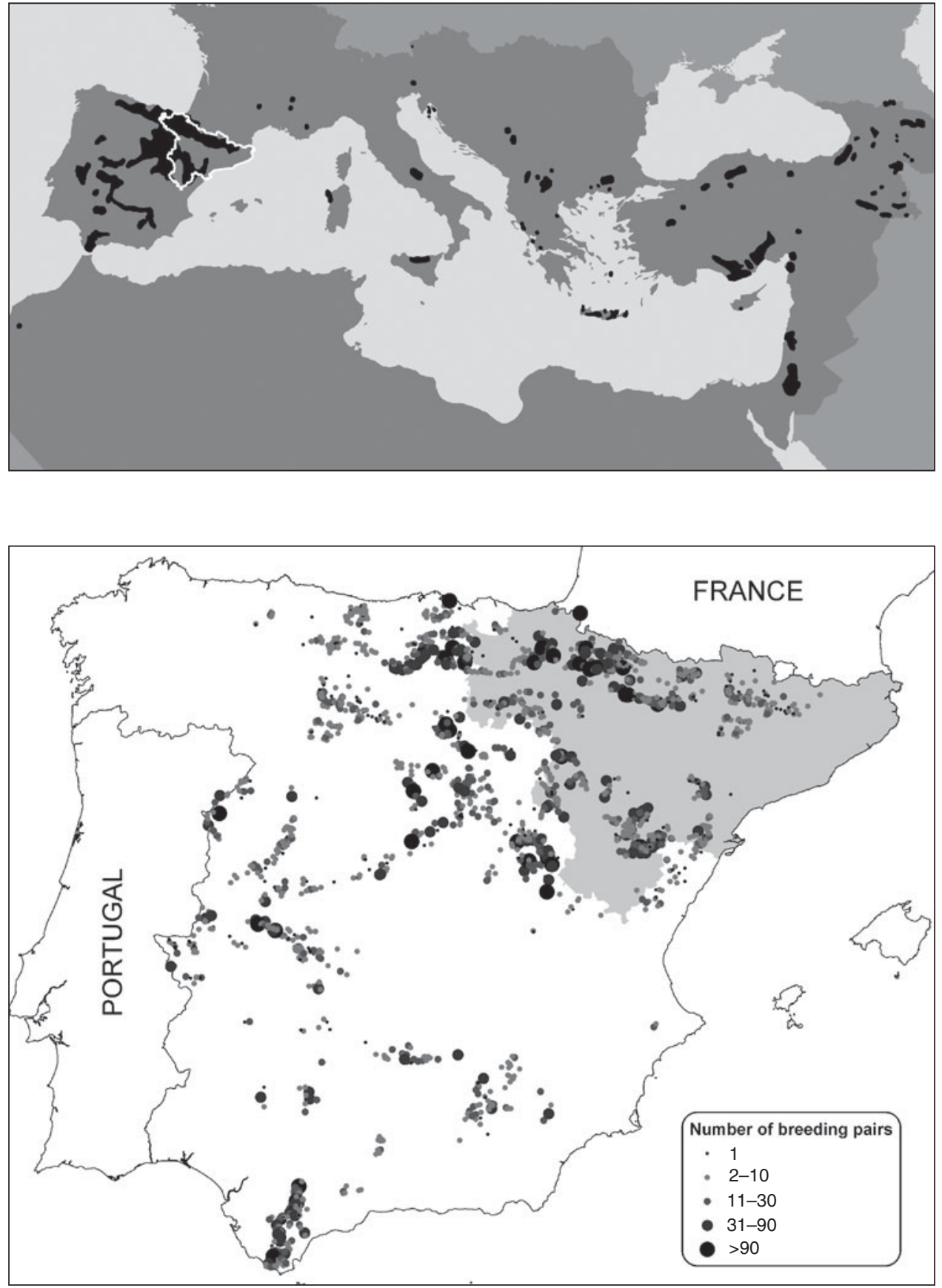

FIG. 1 Study area (encompassed by white line) and circum-Mediterranean distribution (shaded black) of the Eurasian griffon vulture Gyps fulvus population.
FIG. 2 Distribution of griffon vulture colonies in Spain in 2008. Circle size denotes colony size (number of breeding pairs). The study area is shaded grey (modified from Del Moral, 2009).

\section{Quantifying the impact of vulture attacks on livestock}

Although aggressive interactions between vultures and livestock have been documented throughout Spain and southern France, for an initial diagnosis of the phenomenon we selected an area of $78,000 \mathrm{~km}^{2}$ in north-east Spain. During our study period (1996-2010) most of the reported attacks on livestock attributed to griffon vultures in Spain were concentrated in this zone (Fig. 1). The local griffon vulture population has experienced continuous growth and in 2008 was estimated at 7,433 pairs, constituting $27.3 \%$ of the vulture population in the European Union (Fig. 2; Margalida et al., 2010). This area is characterized by the presence of abundant livestock (an estimated 709,294 cows, $3,236,333$ sheep, 109,118 goats and 24,772 horses; MAGRAMA, 2012). Most of this livestock is reared extensively and their numbers increase in the mountains during June-September because of transhumance. Throughout the study area there were supplementary feeding stations for avian scavengers, supplied mainly by intensive farming (Donázar et al., 2009b). Traditionally, livestock carcasses were left in the field to be consumed by vultures but after the outbreak of bovine spongiform 


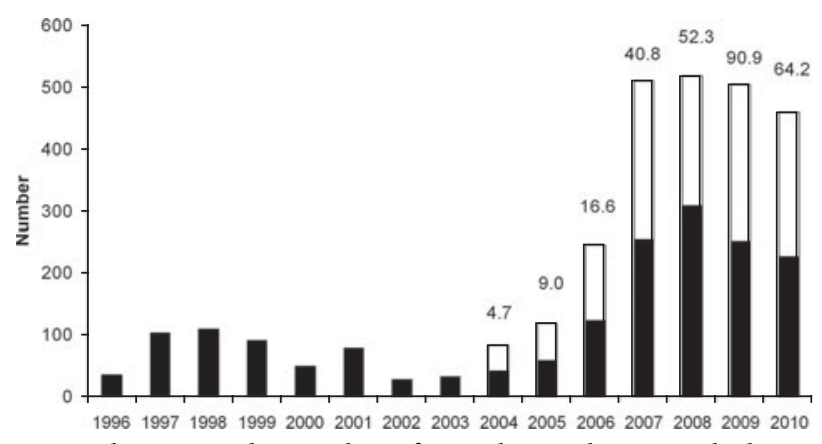

FIG. 3 Changes in the number of complaints about attacks by griffon vultures on livestock received in the study area in northeast Spain (Fig. 2) during 1996-2010. Data on the proportion of complaints accepted (white bars) were not available before 2004 . The cost of compensation (1,00os EUR) is shown above the bars.

encephalopathy (BSE) in 2001 there was a shortage of domestic carcasses generally and at feeding stations in Spain (Donázar et al., 2009a; Margalida et al., 2012). This shortage was pronounced from 2006 onwards following increasingly effective application of European sanitary regulations, and it is estimated that the number of carcasses available to vultures decreased by $80 \%$ in the study area (Cortés-Avizanda et al., 2010; Margalida et al., 2014).

We compiled data from all complaints made to the regional authorities responsible for the management of livestock and wildlife during 1996-2010. Cases of apparent predation of livestock by vultures were generally reported to the authorities by forest rangers, and because of the existence of monetary compensations we are confident that virtually all of the potential livestock losses related to griffon vultures were communicated. Following a complaint lodged by a farmer, authorities sent administrative staff (technical experts and/or forest rangers and veterinarians), if necessary, to evaluate the damage. A complaint was accepted and the farmer compensated if clear evidence was found (i.e. wounds, bruises) demonstrating that the animal was still alive when the vultures began to eat.

Between 1996 and 2010 there were 1,793 reported cases of vulture attacks on livestock in the study region. The number of successful compensation claims for vulture attacks increased with time $\left(r_{\mathrm{s}}=0.55, \mathrm{P}<0.025, \mathrm{n}=15\right.$; Fig. 3). Most cases occurred after 2006 when supplementary feeding stations were closed. On average $69 \%$ of the complaints presented each year were rejected (range 57.6-73.8\%). Most of the cases $(60 \%)$ were reported between April and June and in $36 \%$ of cases the attack appeared to be associated with birthing, generally affecting young and occasionally the mother. The majority of complaints involved sheep (49\%), followed by cows (31\%) and horses (11\%). The economic cost of the compensations assessed during 2004-2010 was EUR 278,590 (Fig. 3).

\section{A conflict with multiple causes?}

The opportunistic killing of small- and medium-sized vertebrates has been reported as relatively frequent for some New World vulture species (Lowney, 1999; Avery \& Cummings, 2004) but has only been reported occasionally for Old World vultures (Houston, 1994). Griffon vultures, however, are obligate scavengers specialized in the consumption of large ungulate carcasses (Houston, 1974). Although before 1990 only anecdotal cases of livestock predation by Eurasian griffon vultures had been reported (Camiña et al., 1995), from the middle of 2000 onwards the number of cases increased across many regions of Spain. A similar scenario developed in the French Pyrenees: between 1993 and 2009 a total of 596 complaints were documented, with $58.2 \%$ of them during 2007-2009 (C. Arthur \& V. Zenoni, unpubl. data).

The availability of food resources may have played a significant role in this apparent behavioural change. In western Europe the appearance of BSE caused food shortages for scavengers as a result of changes in agricultural policies (Donázar et al., 2009a; Margalida et al., 2010). To control the disease the EU promulgated strict regulations regarding the use of animal by-products (Regulation [CE] No. 1774/2002). Although in 2009 and 2010 new regulations in some cases permitted the disposal of carcasses to feed avian scavengers (Margalida et al., 2010, 2012), the global result of the regulations is a strong decrease in food availability that has affected demographic parameters and population growth rates (Margalida \& Colomer, 2012; Margalida et al., 2014) and has caused dietary and behavioural shifts, with vultures now tolerating human presence to within a few metres (Donázar et al., 2009b; Zuberogoitia et al., 2010). Complaints peaked between 2006 and 2010, coinciding with the period of food shortage, supporting the idea that attacks by griffon vultures can be at least partially explained by changes in food availability.

More frequent predation by griffon vultures could also be influenced by changes in husbandry practices. Traditionally in many European countries extensive-grazing livestock were tended by shepherds and dogs, deterring predators (Kaczensky, 1999). However, current practice in many mountain areas of south-western Europe, where large carnivores are absent, is to let livestock range freely or remain unattended in large fenced enclosures, even at the time of lambing. These circumstances increase the chance of predation by small- and medium-sized predators such as canids and other carnivores, common ravens Corvus corax and even wild boars Sus scrofa (authors, unpubl. data). These animals frequently consume available remains, mainly placentas, but may come in contact with and attack weakened animals, both offspring and mothers, something that would not have been possible with the presence of guard dogs and shepherds. Griffon vultures may consume 
the kills of other species and the remains of animals that died at birth, and farmers may consider this opportunistic behaviour as an attack.

In addition to farming practices, increasing griffon vulture populations may have an important role in the observed increase in predation cases; i.e. the probability of interactions may have increased simply as a result of this demographic trend. It is now possible to see vultures breeding and feeding near human habitations and infrastructure (Donázar et al., 2009b). Carcasses are consumed very quickly, often before the farmer has the opportunity to determine the cause of death of the animal, so vultures are sometimes mistakenly characterized as fearless predators responsible for the deaths.

Analysis of the spatial distribution of reported cases of vultures attacking livestock shows that complaints are clustered. This suggests either that phenomena increasing the risk of interactions may be operating at a local scale or that there are clusters of reporting behaviour by farmers. Alternatively, the repeated cases of predation by vultures in well-defined areas could be explained by the existence of specialized problem individuals (Linnell et al., 1999). Not necessarily independent of this, it is possible that these observations may be partially explained by spatial variability in husbandry practices, which could increase the risk of killing events. In addition, the spatial and temporal clustering of the conflict may be influenced by humanrelated factors such as imitation (or patterns of unconscious behaviour) between livestock owners looking for easy compensation.

\section{Discussion}

Considering conflicts between humans and wild animals in general, killing of livestock by griffon vultures is a relatively minor problem. Domestic species, mostly dogs, cause greater damage to livestock than vultures. However, supposedly undesirable vultures are being dealt with using illegal practices such as poisoned bait. Traditionally, these practices were used for carnivores blamed for damage to livestock and game; consequently, most cases of poisoning of scavenger birds were incidental (Hernández \& Margalida, 2008, 2009). However, griffon vultures have now become a target and several cases of intentional poisoning have been detected in the study area, affecting dozens of individuals (Margalida et al., 2011a; Margalida, 2012). This new dimension to the problem is of concern as long-lived species such as avian scavengers are extremely sensitive to unnatural increases in mortality rates, which can quickly lead to the extinction of populations (Oro et al., 2008).

There is a strong current of opinion among managers, governments and some ecologists, attributing the apparent change in the conduct of vultures to lack of food. Although empirical data are scarce (Margalida \& Colomer, 2012), farmers are demanding an increase in the number and size of supplementary feeding sites for vultures to alleviate a perceived scarcity of vulture food (Margalida et al., 2011a,b). The negative perception of the relationship between humans and vultures is an example of how a minor conflict, with few economic repercussions, can change a quasi-mutualistic relationship that has existed for thousands of years (Margalida et al., 2010). Unfortunately, the media find this conflict attractive and the absence of scientific information has facilitated magnification of the perception of the risks of vulture attacks. In the short term, the media must endeavour to use their influence to base public opinion on scientific facts. In the medium and long term, solutions to this emerging conflict need to be agreed by all stakeholders involved, based on accurate information. Livestock farmers, authorities, scientists and conservation groups should then participate in the design and implementation of future strategies for the management of vulture populations, husbandry practices and the availability of carcasses. Recent changes in sanitary policies allowing the presence of livestock carcasses in the field could partially alleviate the human perception of this conflict (Margalida et al., 2012). In addition, in many countries of Europe and North America the conflict between livestock and predators has been minimized by the use of livestock protection dogs (see review in Gehring et al., 2010), which serve as an effective tool to reduce the number of attacks (Espuno et al., 2004; Shivik, 2006).

This type of emerging conflict could also occur between humans and other species that, as a result of conservation strategies, recover rapidly. This could occur in Europe in particular as many populations of large vertebrates are recovering successfully (Deinet et al., 2013) and the gap between wildlife and humans is progressively increasing.

\section{Acknowledgements}

We are grateful to D. García, G. Lampreave, J. Ruiz-Olmo (Generalitat de Catalunya), M. Alcántara (Diputación General de Aragón), J. Carreras (Diputación Foral de Álava), J. Larumbe (Diputación Foral de Navarra), I. Mendiola, M. Olano (Diputación Foral de Gipuzkoa) and M. Razin (LPO, France) for providing data, and J.C. del Moral and M. de la Riva for providing Fig. 2. The comments of two anonymous reviewers improved the article. L. Bortolotti kindly revised the English. AM was supported by a Ramón y Cajal research contract from the Ministerio de Economía y Competitividad (RYC-201211867). 


\section{References}

Anderson, K. (1997) A walk on the wild side: a critical geography of domestication. Progress in Human Geography, 21, 463-485.

Avery, M.L. \& Cummings, J.L. (2004) Livestock depredations by black vultures and golden eagles. Sheep and Goat Research Journal, 19, 58-63.

Camiña, A., Honrubia, A. \& Senosiaín, A. (1995) Attacks on livestock by Eurasian griffons in northern Spain. Journal of Raptor Research, 29, 214.

Cortés-Avizanda, A., Carrete, M. \& Donázar, J.A. (2010) Managing supplementary feeding for avian scavengers: guidelines for optimal design using ecological criteria. Biological Conservation, $143,1707-1715$.

Deinet, S., Ieronymidou, C., McRae, L., Burfield, I.J., Foppen, R.P., Collen, B. \& Böнm, M. (2013) Wildlife Comeback in Europe: The Recovery of Selected Mammal and Bird Species. Final report to Rewilding Europe by Zoological Society of London, BirdLife International and the European Bird Census Council. London, UK.

Del Moral, J.C. (2009) El buitre leonado en España. Población reproductora en 2008 y método de censo. SEO/BirdLife, Madrid, Spain.

Donázar, J.A., Margalida, A. \& Campión, D. (2009b) Vultures, Feeding Stations and Sanitary Legislation: A Conflict and its Consequences from the Perspective of Conservation Biology. Sociedad de Ciencias Aranzadi, Donostia, Spain.

Donázar, J.A., Margalida, A., Carrete, M. \& SánchezZapata, J.A. (2009a) Too sanitary for vultures. Science, 326, 664

Donázar, J.A., Naveso, M.A., Tella, J.L. \& Campión, D. (1996) Extensive grazing and raptors in Spain. In Farming and Birds in Europe (eds D.J. Pain \& M.W. Pienkowski), pp. 117-149. Academic Press, Cambridge, UK.

Espuno, N., Lequette, B., Poulle, M.L., Migot, P. \& Lebreton, J.D. (2004) Heterogeneous response to preventive sheep husbandry during wolf recolonization of the French Alps. Wildlife Society Bulletin, 32, 1195-1208.

Gehring, T.M., VerCauteren, K.C. \& Landry, J.M. (2010) Livestock protection dogs in the 21st century: is an ancient tool relevant to modern conservation challenges? BioScience, 60, 299-308.

Graham, K., Beckerman, A.P. \& Thirgood, S. (2005) Human-predator-prey conflicts: ecological correlates, prey losses and patterns of management. Biological Conservation, 122, 159-171.

Hernández, M. \& Margalida, A. (2008) Pesticide abuse in Europe: effects on the cinereous vulture (Aegypius monachus) population in Spain. Ecotoxicology, 17, 264-272.

Hernández, M. \& Margalida, A. (2009) Poison-related mortality effects in the endangered Egyptian vulture (Neophron percnopterus) population in Spain: conservation measures. European Journal of Wildlife Research, 55, 415-423.

Houston, D.C. (1974) The role of griffon vultures Gyps africanus and Gyps ruppellii as scavengers. Journal of Zoology, $172,35-46$.

Houston, D.C. (1994) Family Cathartidae (New World vultures). In Handbook of the Birds of the World (Vol. 2): New World Vultures to Guineafowl (eds J. del Hoyo, A. Elliott \& J. Sargatal), pp. 24-41. Lynx Edicions, Barcelona, Spain.
KaCZensky, P. (1999) Large carnivore depredation in livestock in Europe. Ursus, 11, 59-72.

Linnell, J.D.C., Odden, J., Smith, M.E., Aanes, R. \& Swenson, J.E. (1999) Large carnivores that kill livestock: do 'problem individuals' really exist? Wildlife Society Bulletin, 27, 698-705.

Lowney, M.S. (1999) Damage by black and turkey vultures in Virginia, 1990-1996. Wildlife Society Bulletin, 27, 715-719.

Magrama (Ministerio de Agricultura, Alimentación y Medio Ambiente) (2012) Http://www.magrama.gob.es/es/ [accessed May 2012].

Margalida, A. (2012) Baits, budget cuts: a deadly mix. Science, 338, 192.

Margalida, A., Campión, D. \& Donázar, J.A. (2011a) European vultures' altered behaviour. Nature, 480, 457.

Margalida, A., Carrete, M., Sánchez-Zapata, J.A. \& DonÁZAr, J.A. (2012) Good news for European vultures. Science, 335, 284.

Margalida, A. \& Colomer, M.A. (2012) Modelling the effects of sanitary policies on European vulture conservation. Scientific Reports, 2, 753 .

Margalida, A., Colomer, M.A. \& Oro, O. (2014) Man-induced activities modify demographic parameters in a long-lived species: effects of poisoning and health policies. Ecological Applications. Http://dx.doi.org/10.1890/13-0414.1.

Margalida, A., Colomer, M.A. \& SAnuy, D. (2011b) Can wild ungulate carcasses provide enough biomass to maintain avian scavenger populations? An empirical assessment using a bioinspired computational model. PLoS One, 6, e20248.

Margalida, A., Donázar, J.A., Carrete, M. \& SánchezZAPATA, J.A. (2010) Sanitary versus environmental policies: fitting together two pieces of the puzzle of European vulture conservation. Journal of Applied Ecology, 47, 931-935.

Oro, D., Margalida, A., Carrete, M., Heredia, R. \& DONÁZAR, J.A. (2008) Testing the goodness of supplementary feeding to enhance population viability in an endangered vulture. PLoS One, 3, e4084.

Peterson, M.N., Birckhead, J.L., Leong, K., Peterson, M.J. \& Peterson, T.R. (2010) Rearticulating the myth of human-wildlife conflict. Conservation Letters, 3, 74-82.

Sekercioglu, C.H., Daily, G.C. \& Ehrlich, P.R. (2004) Ecosystem consequences of bird declines. Proceedings of the National Academy of Sciences of the USA, 101, 18042-18047.

SHIVIK, J.A. (2006) Tools for the edge: what's new for conserving carnivores. BioScience, 56, 253-259.

Treves, A., Wallace, R.B. \& White, S. (2009) Participatory planning of interventions to mitigate human-wildlife conflicts. Conservation Biology, 23, 1577-1587.

Zuberogoitia, I., Martínez, J.E., Margalida, A., Gómez, I., Azkona, A. \& Martínez, J.A. (2010) Reduced food availability induces behavioural changes in griffon vulture. Ornis Fennica, 87, 52-60.

\section{Biographical sketches}

Antoni Margalida is interested in the behavioural ecology and conservation biology of threatened species, particularly avian scavengers. DAVID CAMPIÓN's interests are in management and conservation of threatened species. José A. DONÁZAR's research in conservation biology focuses on long-lived vertebrates. 